\title{
EFEKTIFITAS PENDIDIKAN KESEHATAN TERHADAP PENGETAHUAN DAN PSIKOMOTOR IBU TENTANG PIJAT BAYI DI WILAYAH KERJA PUSKESMAS SUKARAYA KABUPATEN OGAN KOMERING ULU
}

\author{
EFFECTIVENESS OF HEALTH EDUCATION ON THE KNOWLEDGE AND \\ PSYCHOMOTOR OF MOTEHR ABOUT BABY MASSAGE AT PUBLIC HEALTH \\ CENTER OGAN KOMERING ULU REGENCY
}

\author{
Siska Delvia ${ }^{1}$, Muhammad Hasan Azhari ${ }^{2}$ \\ ${ }^{1}$ Sekolah Tinggi Ilmu Kesehatan Al Ma'arif Baturaja, Sumatera Selatan, Indonesia \\ ${ }^{2}$ Akademi Keperawatan Kesdam II/ Sriwijaya, Sumatera Selatan, Indonesia \\ (email penulis korespondensi: siska.delvia26@ gmail.com)
}

\begin{abstract}
ABSTRAK
Latar Belakang: Pengalaman pijat pertama yang dialami oleh manusia ialah pada waktu dilahirkan, yaitu pada waktu melalui jalan lahir ibu. Meskipun bayi belum bisa bicara, tetapi mereka bisa merasakan rangsangan yang diberikan oleh lingkungannya, seperti sentuhan atau pijatan yang diberikan oleh orang tuanya. Penelitian ini bertujuan untuk mengetahui efektifitas pendidikan kesehatan terhadap pengetahuan dan psikomotor ibu tentang pijat bayi di wilayah kerja puskesmas sukaraya.

Metode: Penelitian dilakukan dengan metode eksperimen semu dengan rancangan pre-post eksperimental, dengan jumlah sampel 33 ibu. Penelitian ini dimulai pada tahun 2019 dengan pengambilan sampel secara total sampling. Pengolahan data mengunakan sistem komputerisasi dan dilakukan analisis secara univariat dan bivariat dengan uji Wilcoxon.

Hasil: uji statistik menunjukkan adanya pengaruh yang bermakna (signifikan) antara pendidikan kesehatan terhadap pengetahuan $(\mathrm{p} v=0,000)$, namun tidak ada pengaruh pendidikan kesehatan terhadap psikomotor ( $\mathrm{p} \mathrm{v}=0,089)$.

Kesimpulan: Diharapkan pelayanan kesehatan dapat meningkatkan pendidikan, pembinaan kesehatan, dan program pelatihan tentang pijat bayi melalui kader-kader kesehatan, sehingga masyarakat terutama ibu-ibu dapat menjaga dan meningkatkan kualitas kesehatan bayi mereka.
\end{abstract}

Kata kunci: pengetahuan, psikomotor, pijit bayi

\section{ABSTRACT}

Background: The benefits of this baby massage are that it can help the growth and development of the baby. To be able to give a good massage mothers must have knowledge and psychomotor about baby massage. Therefore, mothers need to be given health education so that mothers can have better knowledge and psychomotor and can use it. This study aims to determine the effectiveness of health education on mothers' knowledge and psychomotor about infant massage in the working area of the Sukaraya Community Health Center.

Methods:The study was conducted with a quasi-experimental method in the form of an experimental pre-post design, with a sample of 33 mothers. This research began in 2019 with total sampling. Data processing using a computerized system and carried out univariate and bivariate analysis with the Wilcoxon test.

Results: Statistical test results showed a significant (significant) effect between health education on knowledge $(p v=0,0005)$, but there was no effect of health education on psychomotor $(p v=0.089)$.

Conclusion: It is expected that health services can improve education, health development, and training programs on infant massage through health cadres, so that the community, especially mothers, can maintain and improve the quality of their baby's health.

Keywords: knowledge, psychomotor, baby massage 


\section{PENDAHULUAN}

Perkembangan bayi untuk menjadi bayi hebat, diawali dari bayi saat berada dalam kandungan dan akan berlanjut setelah bayi itu lahir. Salah satu syarat kunci keberhasilan adalah pada saat bayi lahir dan pada awal kehidupannya. Untuk mencapai keberhasilan tersebut adalah adanya stimulasi. Contoh stimulasi adalah dengan memberikan pijat bayi. $^{1}$

Pengalaman pijat pertama yang dialami manusia ialah pada waktu dilahirkan, yaitu pada waktu melalui jalan lahir. Proses kelahiran adalah suatu pengalaman traumatik bagi bayi karena bayi yang lahir harus meninggalkan rahim yang hangat, aman, nyaman dan dengan keterbatasan ruang gerak menuju kesuatu dunia dengan kebebasan gerak tanpa batas, yang menakutkan, tanpa sentuhan- sentuhan yang nyaman dan aman disekelilingnya, seperti halnya ketika berada di dalam rahim. ${ }^{2}$

Sentuhan dan pijat pada bayi setelah kelahiran dapat memberikan jaminan adanya kontak tubuh berkelanjutan yang dapat mempertahankan perasaan aman pada bayi. Kulit bayi masih sangat sensitif terhadap rangsangan sehingga sentuhan akan menyebabkan berbagai perubahan positif pada bayi. Sentuhan ini dapat membuatnya tenang dan nyaman ${ }^{3}$. Ilmu pijat bayi tradisional di kalangan masyarakat Indonesia sudah lama dikenal, bahkan sampai saat ini masih dilakukan oleh dukun pijat bayi di daerah. Berbeda dengan pijat bayi tradisional, ilmu pijat bayi yang terbaik adalah dilakukan oleh ibu, ayah atau anggota keluarga bayi. ${ }^{2}$

Pijatan yang dilakukan ibu, ayah, dan anggota keluarga lainnya merupakan sapuan lembut yang ditujukan untuk kesehatan dan pengikat jalinan kasih sayang. Pemijatan yang dilakukan oleh ayah menyebabkan perasaan positif kepada bayi dan ibu. Bayi merasa semakin banyak yang menyayanginya dan selalu dilindungi dengan sentuhan yang berbeda dan hangat, bagi ibu melihat suami memijat bayi adalah pemandangan yang sangat membahagiakan sehingga ibu merasa bangga, nyaman, dan tenang yang secara tidak langsung dapat merangsang hormon yang memproduksi ASI ibu dan ini juga dapat membuat ibu semakin bersemangat merawat bayinya sehingga ikatan batin menjadi kuat. ${ }^{3}$

Pijat bayi merupakan salah satu alternatif sebagai upaya untuk mencapai tumbuh kembang anak yang optimal, karena pijat bayi bisa dilakukan sendiri oleh orang tua kapan saja, di rumah, tidak butuh biaya. Berdasarkan studi pendahuluan di Poli KIA RSK St. Vincentius A. Paulo Surabaya yang dilakukan pada 25 ibu yang mempunyai bayi didapatkan hasil bahwa $3(12,00 \%)$ ibu memijat bayinya sendiri dan $22(88,00 \%)$ ibu tidak pernah melakukan pijat bayi dan memijatkan bayinya di dukun bayi bila bayinya sedang sakit saja. ${ }^{5}$

Ibu-ibu akan dapat melakukan pijat bayi secara baik dan benar, bila ibu memiliki pengetahuan. Peningkatan pengetahuan akan menimbulkan kesadaran dan menyebabkan perubahan perilaku, perilaku yang didasari oleh pengetahuan akan bersifat langgeng.

Agar ibu atau masyarakat dapat merubah perilaku atau mengadopsi perilaku kesehatan, perlu adanya peningkatan pengetahuan dengan cara pendidikan kesehatan.

Pendidikan kesehatan adalah upaya agar masyarakat berperilaku atau mengadopsi perilaku kesehatan dengan cara persuasi, bujukan, imbauan, ajakan, memberikan informasi, memberika kesadaran ${ }^{7}$.

Dalam rangka pembinaan dan peningkatan perilaku kesehatan masyarakat, pendidikan kesehatan merupakan upaya kesehatan yang mempunyai peranan penting dalam memberikan pengetahuan dan menerapkan perilaku sehat sehingga meningkatkan kualitas kesehatan ${ }^{7}$. Hasil penelitiaan tentang pengaruh pendidikan kesehatan terhadap tingkat pengetahuan ibu tentang pijat bayi di RSAB Gajayana menunjukkan terjadi peningkatan pengetahuan, dimana sebelum diberikan 
pendidikan kesehatan $45 \%$ responden memiliki tingkat pengetahuan cukup dan setelah diberikan pendidikan kesehatan menjadi $15 \% .^{8}$ Responden dengan tingkat pengetahuan baik sebelum diberikan pendidikan kesehatan 20\% dan setelah diberikan pendidikan kesehatan meningkat menjadi $80 \%$. Responden yang memiliki tingkat pengetahuan kurang sebelum diberikan pendidikan kesehatan $35 \%$ dan

\section{METODE}

Penelitian ini menggunakan pendekatan quasi eksperimen dengan rancangan pra-pascatest (One-group pra-post test design). ${ }^{9}$ Penelitian dilaksanakan pada Maret tahun 2019. setelah diberikan pendidikan kesehatan menjadi $5 \%$ saja.

Berdasarkan laporan bulanan data kependudukan kelurahan 30 Ilir di dapatkan 16 RW dan 60 RT dengan jumlah penduduk 26.644 orang dan jumlah kepala keluarga sebanyak 5.620 KK. Berdasarkan hasil survey pendahuluan terhadap $10 \mathrm{ibu}$, ratarata bayi diberikan terapi pemijatan oleh dukun pijat tradisional, dan pemijatan dilakukan ketika sakit saja.

Data dikumpulkan melalui wawancara menggunakan kuesioner. Analisis data dilakukan dengan cara univariat dan bivariat menggunakan uji t.

\section{HASIL}

Tabel. 1 Distribusi Rata-Rata Pengukuran Pengetahuan Sebelum dan Setelah Diberikan Pendidikan Kesehatan UPTD Puskesmas Sukaraya

\begin{tabular}{cccc}
\hline $\begin{array}{c}\text { Perbandingan Sebelum dan Setelah } \\
\text { Diberikan Pendidikan Kesehatan }\end{array}$ & Jumlah & Persentase (\%) & pvalue \\
\hline $\begin{array}{c}\text { Pengetahuan Setelah intervensi } \\
\text { Pengetahuan sebelum Intervensi }\end{array}$ & 0 & 0 & \\
$\begin{array}{c}\text { Pengetahuan Setelah intervensi }> \\
\text { Pengetahuan sebelum Intervensi }\end{array}$ & 22 & 66,7 & 0,000 \\
$\begin{array}{c}\text { Pengetahuan Setelah intervensi } \\
\text { Pengetahuan sebelum Intervensi }\end{array}$ & 11 & 33,3 & \\
\hline
\end{tabular}

Berdasarkan tabel 1 menunjukkan perbedaan pengetahuan sebelum dan setelah diberikan pendidikan kesehatan, terdapat 22 orang $(66,7 \%)$ mengalami peningkatan pengetahuan setelah diberikan pendidikan kesehatan, 11 orang $(33,3 \%)$ yang setelah diberikan pendidikan kesehatan memiliki pengetahuan yang sama dengan pengetahuan sebelum diberikan pendidikan kesehatan, dan tidak seorang pun setelah diberikan pendidikan kesehatan pengetahuannya lebih rendah dari sebelum diberikan pendidikan kesehatan

Tabel 2. Distribusi Rata-Rata Pengukuran Psikomotor Sebelum dan Setelah Diberikan Pendidikan Kesehatan di Puskesmas Sukaraya

\begin{tabular}{cccc}
\hline $\begin{array}{c}\text { Perbandingan Sebelum dan Setelah } \\
\text { Diberikan Pendidikan Kesehatan }\end{array}$ & Jumlah & Persentase (\%) & p value \\
\hline $\begin{array}{c}\text { Psikomotor Setelah intervensi } \\
\text { Psikomotor sebelum Intervensi }\end{array}$ & 7 & 21,2 & \\
$\begin{array}{c}\text { Psikomotor Setelah intervensi } \\
\text { Psikomotor sebelum Intervensi }\end{array}$ & 12 & 36,4 & 0,089 \\
$\begin{array}{c}\text { Psikomotor Setelah intervensi }= \\
\text { Psikomotor sebelum Intervensi }\end{array}$ & 14 & 42,4 & \\
\hline
\end{tabular}


Perbedaan tingkat pengetahuan dan psikomotor sebelum dan setelah diberikan pendidikan kesehatan. Dari tabel diatas didapatkan 14 orang $(42,4 \%)$ memiliki psikomotor yang sama sebelum maupun setelah diberikan pendidikan kesehatan, 12 orang

\section{PEMBAHASAN}

Tingkat pengetahuan baik sebelum diberikan pendidikan kesehatan 20\% dan setelah diberikan pendidikan kesehatan meningkat menjadi $80 \%$. Setelah diberikan pendidikan kesehatan menjadi 5\%. Hal ini dikarenakan sebagian besar responden berpendidikan tinggi (61\%) dan berumur 20-35 tahun (79\%) sehingga cukup matang dalam berfikir. Selain itu juga dikarenakan sebagian besar responden bertempat tinggal di perkotaan sehingga akan lebih mudah untuk mendapatkan informasi baik dari media cetak maupun media elektronik. Ditunjang pula banyaknya tersedia fasilitas pelayanan kesehatan, sehingga informasi dapat diperoleh dari petugas kesehatan. Semakin cukup umur tingkat kematangan dan kekuatan seseorang akan lebih matang dalam berfikir dan bekerja. Hal ini sebagai akibat dari pengalaman dan kematangan jiwanya. Kemampuan berfikir kreatif mencapai puncaknya dalam umur dua puluhan. ${ }^{16}$ Semakin tinggi pendidikan seseorang semakin mudah orang tersebut menerima informasi yang disampaikan sehingga dapat diasumsikan pendidikan seseorang akan mempengaruhi pengetahuannya. ${ }^{17}$

Pengetahuan responden yang baik ditunjukkan dengan responden mengetahui tentang pijat bayi meliputi pengertian, manfaat, waktu yang tepat untuk memijat, suasana dan ruangan yang nyaman, alat yang harus disiapkan, posisi yang tepat, cara dan langkah-langkah memijat bayi (kemampuan memijat bayi).

Secara umum semua psikomotor responden tidak ada yang baik. Penelitian ini sejalan dengan. Ini terjadi karena responden tidak memiliki pengetahuan yang baik tentang pijat bayi sehingga tidak pernah melakukan pijat bayi dan memijatkan bayinya pada dukun bayi bila bayinya sedang sakit saja. ${ }^{15} \mathrm{Hal}$ ini disebabkan karena untuk merubah perilaku seseorang atau membuat seseorang berbeda dari keadaan sebelumnya terutama perubahan yang terjadi karena terpaksa sedikit sulit dan
$(36,4 \%)$ setelah diberikan pendidikan kesehatan memiliki psikomotor yang lebih baik dari pada sebelum diberikan pendidikan kesehatan., dan 7 orang $(21,2 \%)$ yang setelah diberikan pendidikan kesehatan psikomotornya lebih rendah dari sebelum diberikan pendidikan kesehatan.

memerlukan waktu yang lama, selain itu media untuk penyampaian informasi cara pemijatan menggunakan media elektronik berupa video yang diikuti dengan simulasi sehingga menyebabkan perhatian yang tidak fokus. Media yang digunakan dalam menyampaikan informasi juga mempengaruhi daya tangkap dan serap responden. Oleh sebab itu penyampaian informasi akan berjalan efektif apabila pemberian pendidikan kesehatan direncanakan dengan baik, menggunakan metode yang tepat dengan dukungan media atau alat peraga yang sesuai.

Ibu-ibu akan dapat melakukan pijat bayi secara baik dan benar bila ibu memiliki pengetahuan. Peningkatan pengetahuan akan menimbulkan kesadaran dan menyebabkan perubahan perilaku, karena perilaku yang didasari oleh pengetahuan akan bersifat langgeng. ${ }^{6}$

Ada pengaruh yang positif dan signifikan dari pendidikan kesehatan terhadap pengetahuan terjadi karena pendidikan kesehatan telah mampu memperluas wawasan, pengetahuan ibu-ibu dalam hal pijat bayi. Melalui pendidikan kesehatan akan terjadi proses komunikasi dan pertukaran informasi antara petugas kesehatan dengan kelompok sasaran. ${ }^{18}$

Proses komunikasi dan pertukaran informasi ini akan berjalan efektif apabila pendidikan kesehatan direncanakan dengan baik, menggunakan metode yang tepat dengan dukungan media atau alat peraga yang sesuai. Memang sangat disadari bahwa tingkat pendidikan dan latar belakang pekerjaan kelompok sasaran memiliki pengaruh terhadap daya serap maupun daya tangkap terhadap pesanpesan atau informasi yang disampaikan oleh penyuluh.

Pengaruh dari faktor-faktor secara umum tidak menjadi kendala atau faktor pengganggu yang menjadikan pendidikan/ penyuluhan kesehatan tidak diperlukan di masyarakat. Tingkat pendidikan dan latar belakang 
pendidikan akan tidak banyak berarti bila kelompok sasaran penyuluhan memiliki minat baca yang tinggi, serta perhatian dan peran dalam tanya jawab/diskusi yang baik. Artinya walaupun tingkat pendidikan rendah dan berlatar belakang pekerjaan sebagai buruh cuci, tetap saja hasil post test nya tinggi, tidak jauh berbeda dengan yang berpendidikan lebih tinggi dengan latar belakang pekerjaan sebagai pegawai atau karyawan kantor.

Hasil penelitian pada psikomotor menunjukkan tidak adanya perbedaan psikomotor ibu antara sebelum dan setelah diberikan pendidikan kesehatan. Hal ini dikarenakan untuk

\section{KESIMPULAN DAN SARAN}

Pendidikan kesehatan sangat efektif dalam meningkatkan pengetahuan dan psikomotor ibu tentang pijat bayi. Oleh karena itu penting

\section{DAFTAR PUSTAKA}

1. Luize.2007. Sentuhan Yang Menyehatkan. AyahBunda.

2. Roesli, U.2001. Pedoman Pijat bayi Edisi Revisi. Jakarta: Trubus Agriwidya

3. Subakti, Y \& Anggraini. 2008. Keajaiban Pijat Bayi \& Balita. Jakarta: WahyuMedia.

4. Sari, A. 2004. Pengaruh Penyuluhan Pijat Bayi Terhadap Pengetahuan dan Sikap Ibu Tentang Pijat Bayi di Dusun Dukuh Desa Sidokarto Godean Sleman, Skripsi Program Pendidikan D-IV Kebidanan. Yogyakarta: UGM.

5. Ayurai. 2009. Pijat Bayi. http://Pijat Bayi « Bidanku...Sahabatku.htm. 1 November 2009

6. Mubarok, W.I,. Chayatin, N., Rozikin, K \& Supradi. 2007. Promosi Kesehatan Sebuah Pengantar Proses Belajar Mengajar dalam Pendidikan. Yogyakarta: Graha Ilmu.

7. Notoatmodjo, S. 2003. Pengantar Pendidikan Kesehatan dan Ilmu Perilaku Kesehatan. Yogyakarta: Andi Offset Yogyakarta.

8. Pinetri, B.Y. 2006. Pengaruh Pendidikan Kesehatan Terhadap Tingkat Pengetahuan Ibu Post Partum di RSAB Gajayana Tentang Pijat Bayi.

9. Arikunto, S.2006. Prosedur Penelitian Suatu Pendekatan Praktik. Ed revisi VI, Jakarta: Rineka Cipta

10. Machfoedz, I.2008. Metodologi Penelitian Bidang Kesehatan, Keperawatan, Kebidanan, Kedokteran. Yogyakarta : Fitramaya. merubah seseorang dalam bertindak atau mengadopsi tindakan yang direncanakan memerlukan waktu yang cukup lama dan latihan yang berulang-ulang, sedangkan psikomotor responden berada pada tingkat respons terpimpin (Guided Response), dimana responden dapat melakukan sesuatu sesuai dengan urutan yang benar dan sesuai dengan contoh bukan pada tingkat mekanisme (Mecanism), dimana seseorang telah dapat melakukan sesuatu dengan benar secara otomatis sesuatu itu sudah merupakan kebiasaan.

dilakukan kegiatan pendidikan kesehatan terkait pijat bayi di puskesms.

11. Nursalam. 2008. Konsep dan Penerapan Metodelogi Penelitian Ilmu Keperawatan Pedoman Skripsi, Tesis, dan Instrumen Penelitian Keperawatan. Jakarta: Salemba Medika.

12. Setiadi. 2007. Konsep Penulisan Riset Keperawatan. Ed.1. Yogyakarta : Graha Ilmu.

13. Hastono, S.2001. Analisa Data. Depok : Fakultas Kesehatan Masyarakat Universitas Indonesia.

14. Dahlan, M.S. 2004. Statistik untuk Kedokteran dan Kesehatan. Jakarta: PT Arkans

15. Suyanto.2008. Riset Kebidanan Metodologi dan Aplikasi. Jogyakarta: Mitra Cendikia.

16. Nursalam. 2007. Manajemen Keperawatan: Aplikasi dalam Praktik Keperawatan Profesional. Jakarta : Salemba Meddika.

17. Nuryati, L. 2006. Pengetahuan Ibu Hamil Tentang Kehamilan Resiko Tinggi Di Polindes Kemuning Desa Tasikmadu Kecamatan

Palang.Tuban.http//www.kuliahbidan.wordpr ss.com. 18 Februari 2010.

18. Kusumawati, D. 2008. Pengaruh Pendidikan Kesehatan terhadap Kemampuan Ibu dalam Deteksi Dini Gangguan Perkembangan Anak Balita di Dusun Taruban Kulon, Tuksono, Sentolo. 